\title{
Identification of targets and new developments in the treatment of multiple sclerosis - focus on cladribine
}

This article was published in the following Dove Press journal:

Drug Design, Development and Therapy

17 June 2010

Number of times this article has been viewed

\section{Clemens Warnke' \\ Heinz Wiend ${ }^{2}$ \\ Hans-Peter Hartung' \\ Olaf Stüve ${ }^{3}$ \\ Bernd C Kieseier' \\ 'Department of Neurology, \\ Heinrich-Heine University \\ Düsseldorf, Germany; ${ }^{2}$ Department \\ of Neurology - Inflammatory \\ Disorders of the Nervous System and \\ Neurooncology, University of Münster, \\ Germany; ${ }^{3}$ Department \\ of Neurology, Dallas VA Medical \\ Center and UT Southwestern \\ Medical Center, Dallas, Texas, USA}

Correspondence: Bernd C Kieseier Department of Neurology, HeinrichHeine University, Moorenstrasse 5, 40225 Düsseldorf, Germany

$\mathrm{Tel}+49-2$ I I-8I I 7079

Fax +49-2 I I-8II 6282

Email bernd.kieseier@uni-duesseldorf.de
Abstract: Orally available disease-modifying drugs for relapsing-remitting multiple sclerosis (MS) represent an unmet need for this chronic and debilitating disease. Among 5 currently investigated drugs at phase 3 clinical stage, promising efficacy data for fingolimod and oral cladribine have recently been published. However, benefits need to be weighed against the risks to define the role of these compounds within current treatment regimens. In this review, data on the efficacy of a promising compound, oral cladribine, are discussed and balanced with known and anticipated risks in a postmarketing era, and finally gives an outlook on the potential place of this drug in treatment algorithms for MS in the future.

Keywords: immunosuppressant, oral drugs, risk-benefit, safety

\section{Introduction}

Multiple sclerosis (MS) is a chronic and debilitating immune-mediated disease of the central nervous system (CNS). MS is not a homogeneous disease entity and therefore, as new therapeutics emerge, will require individual therapy regimens in the future. As a chronic, so far not curable disease, therapy is required for an indefinite - if not life long - period of time. In current concepts of MS treatment, drugs that influence immunological reactions are used to alter the course of this disorder and to finally reduce the grade of disability. MS, most relevant for the development of new treatment options, is a disease of low mortality in a young population and treatment primarily seems to be effective in the early inflammatory state of disease when patients suffer only from a low grade of impairment. In addition, no definite surrogate parameters exist to predict the individual course of disease in its early stages, and the individual grade of disability in the future cannot be anticipated with certainty. Thus, ideal treatment of MS would fulfill the following general criteria:

- maximal efficacy (ideal: cure)

- minimal adverse effects (ideal: none)

- maximal compliance (ideal: 100\%)

- easy dosing regimes.

Currently available first-line therapeutics are characterized by their favorable and well-defined safety profile. Since the early 1990s, these disease-modifying drugs (DMD) have been implemented as treatments for MS. Ever since, interferon beta (IFN $\beta$ ) or glatiramer acetate (GA) has become the standard of care for relapsingremitting MS (RRMS). ${ }^{1}$ Different formulations of IFN $\beta$ are available, including IFN $\beta$-1a for weekly intramuscular (IM) or 3 times weekly subcutaneous (SC) 
administration, or IFN $\beta$-1b SC every other day. GA is a synthetic oligopeptide and requires daily administration. In randomized controlled phase 3 trials, all of these agents showed to be superior to placebo regarding clinical end points. ${ }^{2-15}$ Recently published comparative trials did not provide evidence for superiority of one or the other first-line DMD. ${ }^{16-18}$ In addition, data on comparative paraclinicial efficacy is controversial, ${ }^{12,15,19-24}$ and a possible tendency towards a slight advantage on magnetic resonance imaging (MRI) criteria for IFN $\beta$ compared with GA goes along with slightly unfavorable tolerability rates (mainly higher rate of flulike symptoms). Thus, individual decision for one or the other agent is currently based on the preferred route of application (SC or IM) and the individual tolerability of the agent used. The main advantage of these first-line DMD agents for RRMS is their established positive safety profile. Main drawbacks of these agents are

- limited efficacy

- limited compliance and long-term acceptance by patients.

The latter mainly relates to their SC or IM mode of application. Local adverse effects at the sites of injection impair quality of life and long-term acceptance by patients. ${ }^{25-30}$

Promising new targets in MS therapy have been defined within the last decades and target-specific treatment options became available. Some of these treatment options have been tested in clinical trials, and have shown very promising results regarding efficacy. But, as outlined above, to play a role as first-line therapeutics in MS, these drugs need to display a reasonable safety profile in patients on long-term therapy or even life-long therapy. This matter of risk:benefit ratio became strikingly apparent when natalizumab was introduced in the therapy for MS. Natalizumab was the first drug of rational drug design approved for MS therapy, a humanized monoclonal IgG4-antibody, specifically designed to target a critical step of leukocyte migration into areas of inflammation within the CNS. ${ }^{31,32}$ Phase 3 clinical trials have clearly shown its advantages: high efficacy and high rates of compliance by intravenous (IV) monthly infusion. ${ }^{33,34}$ However, immediately after the completion of a phase 3 trial that led to its approval, safety issues, and most notably the risk of progressive multifocal leukoencephalopathy (PML), became apparent. ${ }^{35-37}$ Restriction of natalizumab to patients with highly active MS or patients, not responding to first-line treatment, was not congruent with the inclusion criteria of these studies but based on risk-benefit considerations. Just recently, new cases of PML occurring in patients receiving natalizumab monotherapy have been published and the long-term safety data might further limit its use in the future. ${ }^{38-40}$ Interestingly, these safety issues are most likely not only restricted to natalizumab but also are relevant for other currently investigated drugs of this second generation of target-specific immunosuppressive monoclonal antibodies. One lesson to be learned from natalizumab and other compounds such as rituximab, efalizumab, or alemtuzumab in drug development is the awareness that target specificity does not guarantee disease-specific efficacy. Although the mode of action of these drugs seems to be highly specific, their administration to young and otherwise healthy patients results in a severe alteration of immunocompetence going along with an increased risk of potential life-threatening infections (eg, risk of PML in natalizumab, efalizumab, ${ }^{41}$ or rituximab) ${ }^{42}$ or autoimmune (eg, risk of autoimmune thrombocytopenia and thyroid disease in alemtuzumab) ${ }^{43}$ complications. Thus, the risk-benefit consideration is crucial and, although low, the risk of a potential life-threatening complication in MS population demands a critical patient selection and high standards of safety surveillance plans.

This is also an issue of concern in the development of new oral drugs for MS treatment. Easy dosing regimens and a convenient mode of administration are the most relevant advantages of this group of drugs. For these reasons, approval of an oral drug would be highly appreciated by patients improving quality of life and increasing adherence to therapy. ${ }^{44,45}$ Among 5 oral therapies currently in phase 3 clinical trials (fingolimod, laquinimod, fumeric acetate, teriflunomide, and oral cladribine; Table 1), fingolimod and oral cladribine have already completed phase 3 clinical trials that were just recently published. ${ }^{46-49}$ In this review, data on efficacy of a promising compound, oral cladribine, are contrasted with known and potential risks. As the manufacturer already applied to the US Food and Drug administration and Europe, the Middle East and Africa for approval, risks and benefits of this drug need to be discussed to define the potential role within established treatment concepts.

\section{Cladribine and its mode of action}

Carson et $\mathrm{al}^{50,51}$ discovered that the lymphopenia observed in an inherited disorder of adenosine deaminase deficiency was caused by the accumulation of deoxyadenosine nucleotides within lymphocytes. Based on this observation, this group started to synthesize therapeutic purine nucleoside analogs, including cladribine (2-chlorodeoxyadenosine), to preferentially target lymphocytes. ${ }^{50,51}$ Cladribine is a prodrug requiring intracellular phosphorylation to become an active purine nucleoside analog. The prodrug is resistant 
Table I Oral drugs in clinical development for multiple sclerosis

\begin{tabular}{|c|c|c|c|}
\hline Drug & $\begin{array}{l}\text { Phase } 3 \text { (indication, } \\
\text { comparator) }\end{array}$ & $\begin{array}{l}\text { Phase } 2 \text { (primary } \\
\text { end point) }\end{array}$ & $\begin{array}{l}\text { Safety profile (most relevant data } \\
\text { from recent clinical experience) }\end{array}$ \\
\hline Cladribine & $\begin{array}{l}\text { (I) CIS, placebo } \\
\text { (2) RRMS, placebo46 } \\
\text { (3) RRMS, add-on to IFN } \beta\end{array}$ & $\begin{array}{l}\text { Not performed for } \\
\text { oral formulation }\end{array}$ & $\begin{array}{l}\text { Lymphocytopenia, exacerbation of herpes } \\
\text { virus infection, one case of tuberculosis } \\
\text { excerbation, single cases of malignancies } \\
\text { (melanoma, pancreas carcinoma, and } \\
\text { ovarian carcinoma) }\end{array}$ \\
\hline Fingolimod & $\begin{array}{l}\text { (1) RRMS, placebo }{ }^{47} \\
\text { (2) RRMS, placebo } \\
\text { (3) RRMS, IFN } \beta^{48} \\
\text { (4) PPMS }\end{array}$ & $\begin{array}{l}\mathrm{MR}^{80} \text { (median total } \\
\text { number of gadolinium- } \\
\text { enhanced lesions on } \\
\text { MRI): } 1.25 \mathrm{mg} \text { or } 5 \mathrm{mg} \\
\text { or placebo: I } \\
(P=0.00 \mathrm{I}) \text { or } 3 \text { lesions } \\
(P=0.006) \text { or } 5 \text { lesions }\end{array}$ & $\begin{array}{l}\text { Lymphocytopenia, exacerbation of herpes } \\
\text { virus infection ( } 2 \text { fatal cases), macula edema, } \\
\text { cardiovascular side effects }\end{array}$ \\
\hline Teriflunomide & $\begin{array}{l}\text { (I) CIS, placebo } \\
\text { (2) RRMS, placebo } \\
\text { (3) RRMS, IFN } \beta\end{array}$ & $\begin{array}{l}\mathrm{MR}^{81} \text { (mean number of } \\
\mathrm{CU} \text { active lesions per } \\
\text { scan): } 7 \text { or } 14 \mathrm{mg} / \text { day: } \\
\text { reduction by } 61 \%\end{array}$ & $\begin{array}{l}\text { Gl symptoms, hepatotoxicity, low risk of } \\
\text { pancytopenia, low risk of endogenous } \\
\text { infections, teratogenicity }\end{array}$ \\
\hline Laquinimod & $\begin{array}{l}\text { (I) RRMS, placebo } \\
\text { (2) RRMS, IFN } \beta\end{array}$ & $\begin{array}{l}\mathrm{MR}^{82} \text { (cumulative } \\
\text { number of active } \\
\text { lesions over } 24 \mathrm{wk} \text { ): } \\
\text { reduction by } 44 \%\end{array}$ & $\begin{array}{l}\text { Iritis and burning sensation; during follow-up } \\
\text { acute tonsillitis, one case of breast cancer }\end{array}$ \\
\hline BG 12 & $\begin{array}{l}\text { (1) RRMS, placebo } \\
\text { (2) RRMS, glatiramer acetate }\end{array}$ & $\begin{array}{l}M{ }^{83} \text { (total number of } \\
\text { new gadolinium- } \\
\text { enhancing lesions on } \\
\text { MRI week } 12 \text { to } 24 \text { ): } \\
\text { reduction by } 69 \%\end{array}$ & $\begin{array}{l}\text { Abdominal pain, flushing, hot flush, } \\
\text { headache, and fatigue }\end{array}$ \\
\hline
\end{tabular}

Abbreviations: $\mathrm{CIS}$, clinically isolated syndrome; CU, combined unique; RRMS, relapsing-remitting multiple sclerosis; MRI, magnetic resonance imaging; PPMS, primary progressive multiple sclerosis; IFN $\beta$, interferon beta.

to degradation by adenosine desaminase and is able to enter cells via purine nucleoside transporters. ${ }^{52}$ Once within the cell, cladribine undergoes initial phosphorylation by deoxycytidine kinase (DCK) to finally become the active 2-chlorodeoxyadenosinetriposphate. ${ }^{53}$ To inactivate cladribine-triphosphate nucleotides and to prevent intracellular accumulation, dephosphorylation by $5^{\prime}$-nucleotidase $\left(5^{\prime}\right.$-NTase) is required. Compared with other cell types, resting and activated lymphocytes have high levels of DCK but low levels of 5'-NTase. Thus, cladribine becomes particularly activated to its active form within lymphocytes making these cell types preferentially vulnerable to its effects. ${ }^{54}$ The accumulation of cladribine nucleotides leads to breaks in DNA strands, interferes with DNA synthesis and repair, and ultimately results in a sustained reduction of lymphocyte counts. ${ }^{55}$ Therefore, the main immunosuppressive effect of cladribine is mediated via immune cell depletion, of both the proliferating and the quiescent lymphocytes. ${ }^{50}$ At doses used in clinical trials for MS, cladribine differentially affects $\mathrm{CD}^{+}, \mathrm{CD}^{+}$, and $\mathrm{CD} 19^{+}$lymphocyte subpopulations, possibly related to differences in the DCK/5' - NTase-ratio. ${ }^{56,57}$ $\mathrm{CD} 4^{+} \mathrm{T}$ cells are preferentially reduced compared with $\mathrm{CD} 8^{+}$
$\mathrm{T}$ cells, resulting in a lower $\mathrm{CD} 4 / \mathrm{CD} 8$ ratio, affecting both naive and memory $\mathrm{T}$ cells. Although $\mathrm{CD} 19^{+} \mathrm{B}$-cell reduction occurs rapidly, recovery from the nadir is seen earlier and more pronounced compared with T cells. ${ }^{56-60}$ Recent evidence indicates that cladribine may also impede the influx of $T$ cells into the CNS, and might also influence levels of soluble adhesion molecular levels such as sICAM or sE-Selectin. ${ }^{61,62}$ In addition, cladribine may exert immunomodulatory effects on proinflammatory cytokine profiles: Mean values of Interleukin-2 (IL-2) and soluble interleukin-2 receptor levels measured 12 months after cladribine treatment for chronic progressive MS were found to be lowered. ${ }^{63} \mathrm{IL}-8$-levels were decreased in cerebrospinal fluid (CSF) of cladribine-treated RRMS patients, whereas CCL-5 levels were decreased both in CSF and serum. ${ }^{64}$ These and other data suggests that cladribine not only has an leukocyte depleting effect, but also may exert a direct effect on effectors T-cell function. ${ }^{59,65}$

\section{Pharmacokinetics of cladribine}

Cladribine is rapidly absorbed and its oral bioavailability varies between $37 \%$ and $51 \% .{ }^{53}$ The terminal half-life varies from 5.7 to 19.7 hours. In CSF, the concentration has been 
reported to be approximately $25 \%$ of that in plasma in patients without CNS disease, indicating the ability of cladribine to cross the blood-brain barrier. The renal clearance of cladribine is about $51 \%$ of total clearance and $21 \%-35 \%$ of an IV-administered dose is excreted un-metabolized in the urine..$^{53}$

\section{Efficacy of cladribine in clinical trials Efficacy data with parenteral cladribine}

Cladribine has been primarily used for reduction of aberrant lymphocyte populations in a variety of hematological disorders, and the parenteral formulation is treatment of choice for hairy cell leukemia. ${ }^{66-68}$ In addition, cladribine has been tested in autoimmune disorders such as rheumatoid arthritis and systemic lupus erythematodus-associated glomerulonephritis. ${ }^{69,70}$ In MS, parenteral cladribine has been evaluated for relapsing or progressive forms. The MS-Scripps-trial ${ }^{71}$ was a 2-year, placebo-controlled, double-blind, crossover study started in 1992 to evaluate cladribine IV for chronic progressive MS. In the first year, patients were given cladribine $0.1 \mathrm{mg} / \mathrm{kg} /$ day IV for 7 days as 4-monthly courses (total dose, $2.8 \mathrm{mg} / \mathrm{kg}$ or placebo). During the second year, patients of the first year's placebo group were given $0.10,0.05$, and $0.05 \mathrm{mg} / \mathrm{kg} / \mathrm{day} \mathrm{IV}$ for 7 consecutive days in 3 successive monthly courses (total dose, $1.4 \mathrm{mg} / \mathrm{kg}$ ). In the Scripps-C-trial, ${ }^{72}$ an 18-month, placebo-controlled, double-blind study in the treatment of patients with RRMS, patients received either placebo or cladribine $0.07 \mathrm{mg} / \mathrm{kg} /$ day SC for 5 consecutive days as 6-monthly courses (total cumulative dose, $2.1 \mathrm{mg} / \mathrm{kg}$ ). In the MS-001-trial, safety and efficacy were evaluated in patients with progressive MS, assigned to receive placebo or cladribine $0.07 \mathrm{mg} / \mathrm{kg} /$ day SC for 5 consecutive days for every 4 weeks for either 2 or 6 cycles (total dose, 0.7 or $2.1 \mathrm{mg} / \mathrm{kg}$ ), followed by placebo for a total of 8 cycles. To summarize, efficacy data of these most relevant phase 2/3 clinical studies in 262 involved patients, parenteral cladribine showed positive results in patients with both relapsing and progressive forms of MS. A total of 183 patients received cumulative doses of $0.7-2.8 \mathrm{mg} / \mathrm{kg}$ of cladribine and individual results were suggestive not only for improvement of MRI-criteria (the number and volume of T1 gadolinium-enhancing lesions, the accumulation of T2 lesion volume), but also for neurological outcome measures (relapse rate and disability progression). Based on this treatment experience, a regimen for oral cladribine was developed and recently investigated in phase 3 clinical trial settings. ${ }^{73}$

\section{Efficacy data with oral cladribine}

\section{The clarity trial}

\section{Study design}

Results of the CLAdRIbine Tablets treating MS orallY (CLARITY) Trial, as one of 3 phase 3 clinical trials for oral drugs for MS to be completed, have been recently published. ${ }^{46}$ CLARITY was performed in a randomized, double-blind, placebo-controlled, multicenter, 96-week setting with 3 parallel groups. Patients with RRMS, ${ }^{74}$ aged 18-65, who had at least 1 relapse within 12 months before study entry, and a score of no more than 5.5 on the Kurtzke Expanded Disability Status Scale (EDSS) ${ }^{75}$ were included. Patients with previous immunosuppressive treatment and patients with abnormal platelet, neutrophil, or leukocyte counts were excluded. In total, between 2005 and 2007, 1,326 patients were assigned in a 1:1:1 ratio to receive either $3.5 \mathrm{mg} / \mathrm{kg}$ or $5.25 \mathrm{mg} / \mathrm{kg}$ or matching placebo. The study drug was administered as short courses, each consisting of one or two 10-mg cladribine tablets or matching placebo given once daily for the first 4 or 5 days. In the $5.25-\mathrm{mg} / \mathrm{kg}$ group, patients received 4 courses of cladribine in the first 48 -week treatment period. In the $5.25-\mathrm{mg} / \mathrm{kg}$-group, patients received 2 courses of cladribine, followed by 2 courses of placebo. Four courses of placebo were administered to the placebo group. In all groups, courses were started at day 1 , followed by courses at weeks 5,9 , and 13 . In the second 48-week period, both cladribine groups received 2 courses of cladribine, and the placebo group received 2 courses of placebo, starting at weeks 48 and 52 (Figure 1). After week 24, rescue therapy with IFN $\beta$-1a SC was available for patients with more than 1 relapse or a sustained increase in the EDSS score.

The primary end point was the rate of relapse at 96 weeks. A relapse was defined as an increase of 2 points in at least 1 functional system of the EDSS or an increase of 1 point in at least 2 functional systems in the absence of fever, lasting for at least 24 hours and to have been preceded by at least 30 days of clinical stability or improvement. Secondary clinical outcome measures were the proportion of patients who were relapse-free, the time to sustained progression of disability (time to a sustained increase of at least 1 point in the EDSS score or an increase of at least 1.5 points if the baseline EDSS score was 0), the time to the first relapse, and the proportion of patients receiving rescue therapy with IFN $\beta$-1a SC. Secondary MRI end points were the mean number of lesions per patient per scan at 96 weeks for gadoliniumenhancing T1-weighted lesions, active T2-weighted lesions, and combined unique lesions (new gadolinium-enhancing 


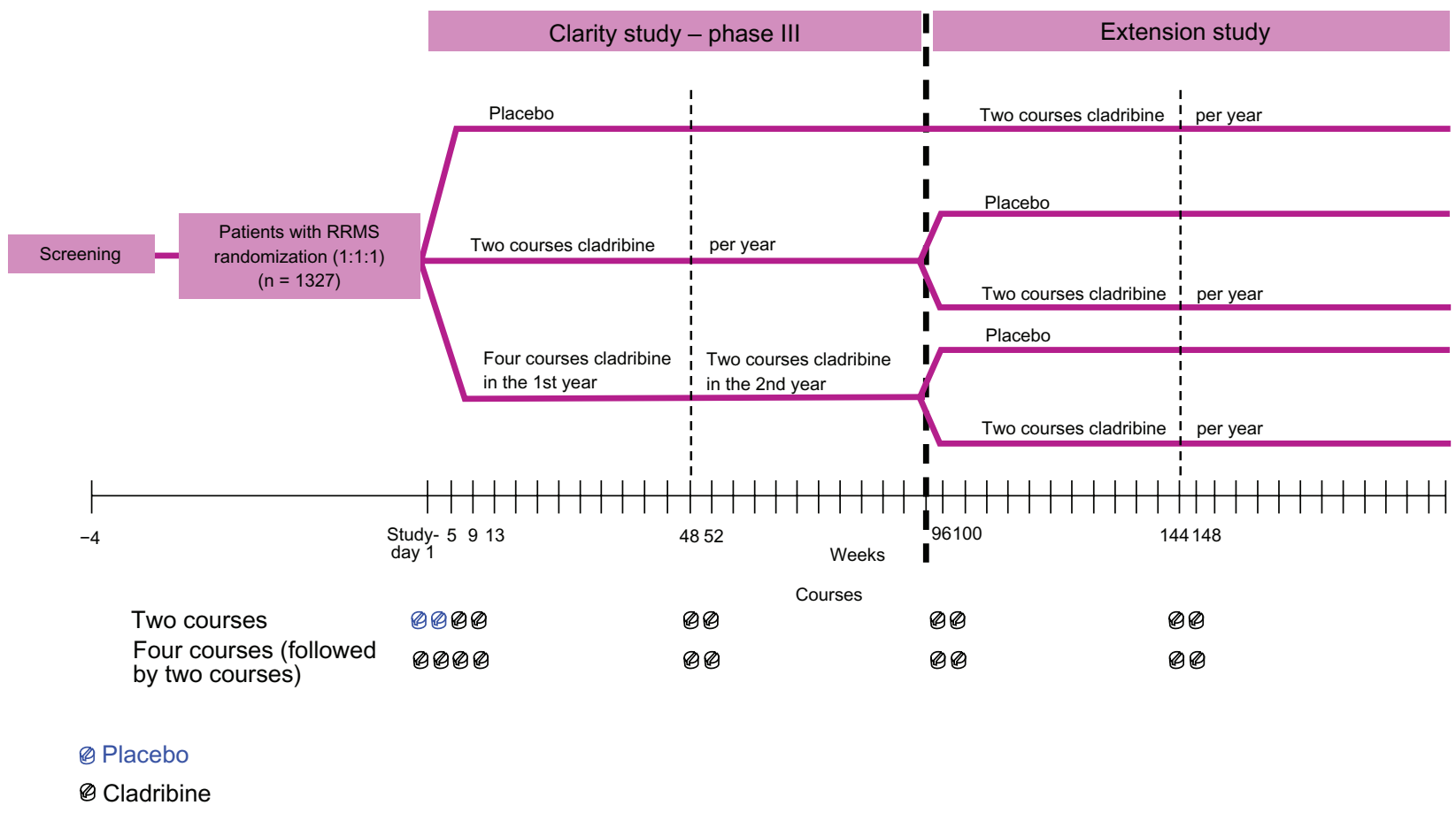

Figure I Study design of the CLARITY study.

T1-weighted lesions or new nonenhancing or enlarging T2-weighted lesions).

\section{Study results}

The annualized relapse rate at 96 weeks was significantly reduced in both treatment groups, as compared with placebo (0.14 in the cladribine $3.5-\mathrm{mg}$ group and 0.15 in the cladribine 5.25 -mg group vs 0.33 in the placebo group; Figure 2). Thus, relative reductions of the annualized relapse rate were $57.6 \%$ and $54.5 \%$, respectively $(P<0.001)$. The proportion of patients who remained relapse-free at 96 weeks was significantly higher in both cladribine groups than in placebo $(79.7 \%$ and $78.9 \%$ vs $60.9 \% ; P<0.001)$. There was a significant relative reduction in the risk of 3-month sustained progression of disability in both cladribine groups, as compared with placebo (33\% reduction for cladribine $3.5 \mathrm{mg}, 31 \%$ reduction for cladribine 5.25-mg group) with corresponding increase in the odds for remaining free of 3-month sustained disability progression. Additional clinical outcome measures, such as the time to the first relapse or the need for rescue therapy with IFN $\beta$-1a SC were also in favor for both of the cladribine treatment groups.

Regarding MRI outcome measures, patients in the cladribine $3.5-\mathrm{mg}$ group and cladribine 5.25-mg group had significant lower mean numbers of lesions per patient per scan than those in the placebo group for gadolinium-enhancing $\mathrm{T} 1$ lesions (0.12 and 0.11 vs 0.91 for placebo), active T2 lesions ( 0.38 and 0.33 vs 1.43 for placebo), and combined unique lesions ( 0.43 and 0.38 vs 1.72 for placebo).

\section{Ongoing phase 3 clinical trials}

Following completion of the CLARITY study, patients are given the opportunity to participate in the 96-week phase $3 \mathrm{~b}$ extension study (ClinicalTrials.gov identifier: NCT00641537; Figure 1). Patients originally randomized to placebo will receive oral cladribine, whereas those originally randomized to cladribine will be rerandomized to either cladribine tablets or placebo. This study has been primarily designed to provide information on the longer term safety and tolerability of oral cladribine administered for an additional third and forth year in patients with RRMS, including clinical laboratory testing, electrocardiograms, and review of adverse events. Clinical efficacy measures are secondary end points to evaluate the sustained effects of treatment. Estimated primary completion date is September 2011.

The Oral Cladribine Added ON To Rebif New Formulation in Patients With Active Relapsing Disease (ONWARD)-trial (ClinicalTrials.gov identifier: NCT00436826) is a 96-week, randomized, double-blind, placebo-controlled, phase $2 \mathrm{~b}$ trial in patients with active MS. This study evaluates the safety and tolerability of oral cladribine compared with placebo as an add-on therapy to IFN $\beta$ treatments in patients with active RRMS or secondary progressive MS with superimposed relapses. Clinical end points and MRI criteria are secondary 


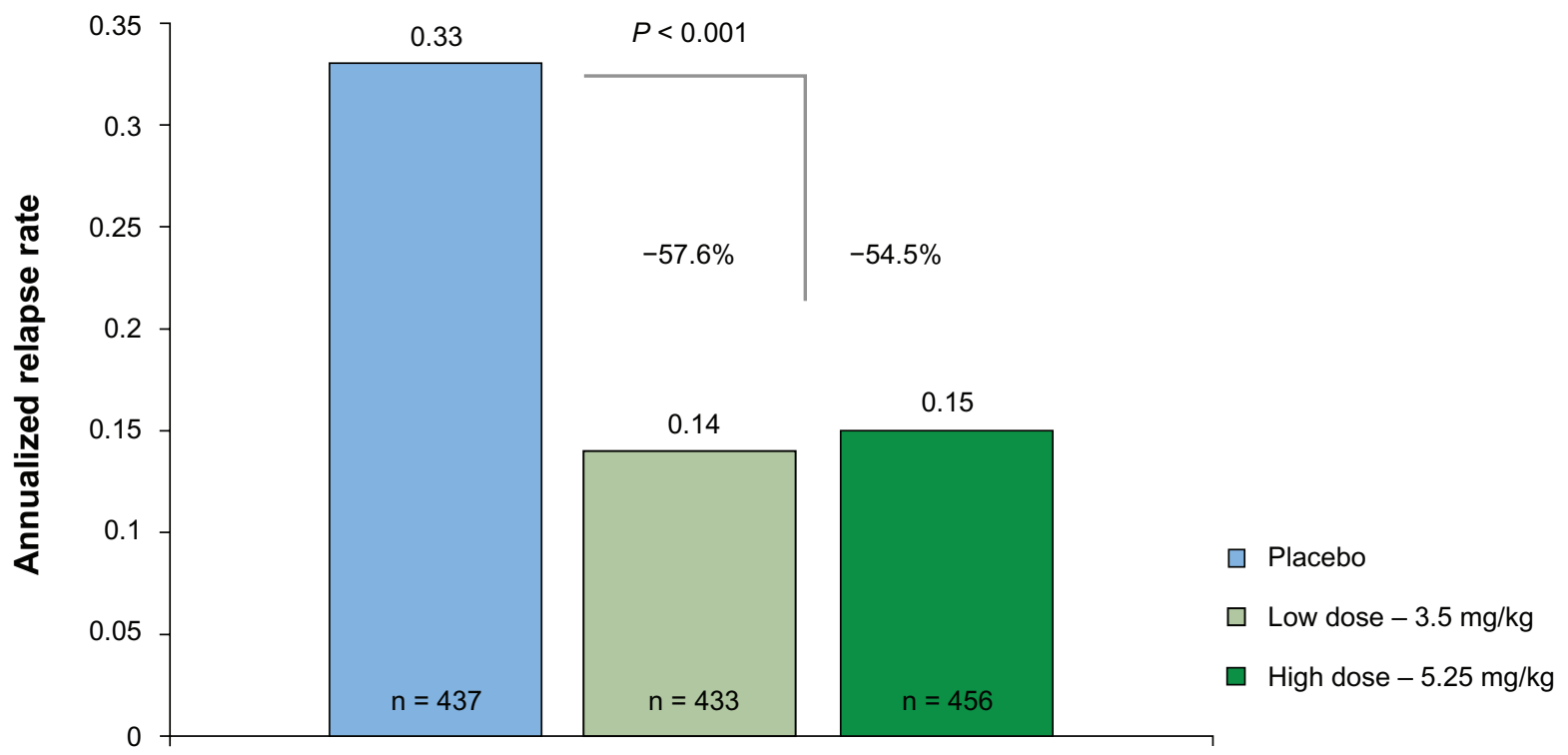

Figure 2 Relapse rate reduction as the primary outcome of the CLARITY study.

outcome measures in this study. Estimated primary completion date is October 2013.

The Oral Cladribine in Early MS (ORACLE) - trial (ClinicalTrials.gov identifier: NCT00725985) is a 96-week randomized, double blind, 3-arm, placebo-controlled, multicenter, phase 3 trial to evaluate the safety and efficacy of oral cladribine vs placebo to prevent or delay conversion to definite MS (revised McDonald criteria) ${ }^{76}$ in patients with a first clinical demyelinating event at high risk of converting to MS. Subjects must have a minimum of 2 clinically silent lesions on the screening MRI. Depending upon the clinical course of their MS, subjects will proceed from the initial treatment period to an open-label IFN $\beta$-period or, if no progression to MS has been noted after the initial treatment period, to either open-label low-dose cladribine or no additional treatment. Estimated primary completion date is October 2012.

\section{The safety and tolerability profile of cladribine}

Parenteral cladribine has been in use for treatment of MS, hematological malignancies, and other indications for over 15 years, providing a comparable established safety profile for the drug. ${ }^{73}$ However, safety data of oncology patients cannot directly be transferred to MS patients, as the former population is often exposed to additional cytotoxic chemotherapy, and both populations are likely to differ in immune competence. Still, from indications other than MS, myelosuppression and infections have been noted. Escalating dose regimens have been associated with, though typically transient, toxicity to stem cells. In particular, patients with poor bone marrow reserve experienced marked thrombocytopenia with repeated dosing. ${ }^{59,63}$ Toxicity seems to be dose-dependant and administration of cladribine at a dosage above the recommended $0.1 \mathrm{mg} / \mathrm{kg}$ has been associated more frequently with myelosuppression, systemic infections, acute nephrotoxicity, and neuropathies. A significantly increased risk of secondary malignancies has not been noted in patients treated with cladribine for lymphoma. ${ }^{68,77,78}$ For treatment of MS with parenteral cladribine, a combined analysis was performed using data from 268 patients enrolled in Scripps-studies. Adverse events occurring most frequently in all groups were upper respiratory tract infections (32\% cladribine group vs $24 \%$ placebo), headaches ( $28 \%$ cladribine group vs $38 \%$ placebo), and injection-site reactions ( $24 \%$ cladribine group vs $25 \%$ placebo). ${ }^{79}$ The incidence of serious adverse events was similar in patients receiving cladribine at doses of $0.7-2.1 \mathrm{mg} / \mathrm{kg}$ or placebo (11-15\% vs $17 \%$ ). ${ }^{79}$ Although parenteral cladribine has shown to be teratogenic in mice and rabbits, there is no direct evidence for teratogenicity in humans. ${ }^{59}$ Nevertheless, this potential side effect needs to be taken into account.

Most valid data derive from the recently published oral CLARITY trial in MS population ${ }^{46}$ As expected from parenteral trials, lymphocytopenia (mostly graded as mild or moderate) is more frequently seen among patients receiving cladribine compared with placebo. Severe neutropenia was reported in 3 patients ( 1 in the 3.5-mg group and 2 in the 5.25 -mg group). In 1 patient of the latter group, severe thrombocytopenia and pancytopenia occurred, associated 
with an exacerbation of latent tuberculosis. Infections or infestations (graded mild or moderate in around 99\% in all groups) were reported in $47.7 \%$ of the patients in the cladribine $3.5-\mathrm{mg}$ group, $48.9 \%$ of those in the cladribine $5.25-\mathrm{mg}$ group, and $42.5 \%$ of those in the placebo group. Herpes zoster infections occurred in 20 cladribine-treated patients ( 8 patients in the $3.5-\mathrm{mg}$ group and 12 in the 5.25 -mg group). All cases of herpes zoster were restricted to neighboring dermatomes, including 1 case of herpes zoster oticus. There were 3 uncomplicated cases of primary varicella, 1 in each study group. Adverse events leading to treatment discontinuation were seen in $3.5 \%$ of patients in the cladribine $3.5-\mathrm{mg}$ group, $7.9 \%$ of those in the cladribine 5.25-mg group, and $2.1 \%$ of those in the placebo group. The incidence of serious adverse events was $8.4 \%$ in the cladribine $3.5-\mathrm{mg}$ group, $9.0 \%$ in the cladribine $5.25-\mathrm{mg}$ group, and $6.4 \%$ in the placebo group. There were 3 cases of malignancies in the cladribine 3.5-mg group (melanoma, pancreas carcinoma, and ovarian carcinoma). One case of cervical carcinoma in situ was also reported in the cladribine 5.25 -mg group in a human papillomavirus type 16 positive individual. A choriocarcinoma was diagnosed in 1 patient in the cladribine $5.25-\mathrm{mg}$ group approximately 9 months after completion of the study. There were 4 deaths during the study and 2 after study discontinuation, equally distributed across the 3 study groups. Causes of death were acute myocardial infarction and metastatic pancreatic carcinoma in the cladribine 3.5-mg group, drowning and cardiopulmonary arrest (considered secondary to exacerbation of latent tuberculosis) in the cladribine 5.25-mg group, and suicide and hemorrhagic stroke in the placebo group.

\section{Perspective: potential of oral formulations in MS treatment with a focus on cladribine}

The long-awaited publication of successful and wellconducted phase 3 clinical trials of oral drugs for RRMS is promising news for more than 2 million people worldwide suffering from this chronic, disabling disease, as well as for their treating physicians. Among 5 currently investigated drugs at phase 3 clinical stage, efficacy and safety data for fingolimod (FTY720 Research Evaluating Effects of Daily Oral therapy in Multiple Sclerosis [FREEDOMS] and Trial Assessing Injectable IFN vs FTY720 Oral in Relapsing Remitting Multiple Sclerosis [TRANSFORMS]) and cladribine (CLARITY) have been recently published. ${ }^{46-49}$ From a patient's perspective, the approval of oral therapies would definitely be appreciated, reducing restrictions on lifestyle and hope for more efficient treatment. Compared with other oral drugs, it is the only therapy with potential of short-course dosing. From the physician's perspective, oral medication may promise improvement of treatment adherence. However, regarding the potential of drugs like cladribine, 3 key questions still need to be answered.

First, is cladribine treatment superior to currently available drugs regarding efficacy? Only head-to-head trials can give firm conclusion on the efficacy of cladribine vs established injectable therapies. These trials still need to be undertaken. Mainly due to the differences in severity of disease, comparing data across clinical trials is extremely problematic. Currently running studies are designed to evaluate cladribine as add-on to IFN $\beta$ and for early MS, but only comparative head-to-head trials will answer this question.

Second, do benefits exceed the risks in a long-term perspective? We do not know by now, whether or not adverse effects seen in the recently published trials of cladribine and fingolimod are the only safety issues to consider. Occurrence of herpes virus infections, as seen among patients receiving cladribine or fingolimod, indicate an alteration of endogenous viral immunosurveillance by these promising orals. In addition, 3 cases of solid tissue cancers (pancreatic, ovarian, and melanoma) occurred among patients receiving cladribine. Keeping in mind the still unsolved and ongoing natalizumab-experience with occurrence of most relevant safety concerns in the postmarketing area, ${ }^{35-40}$ we cannot anticipate the long-term safety from the recently published phase 3 clinical trials. Particularly, with regard to rare opportunistic infections such as PML, only ongoing extension trials such as the CLARTIY-Extension trial and, in case of approval, critical patient selection and high standards of postmarketing safety surveillance programs will enable us to estimate the risk and prevent harm.

Third, what would be the potential role of cladribine within established treatment concepts of RRMS? Similar to natalizumab, not efficacy data from phase 3 clinical trials, but safety data from still running trials and of a potential postmarketing era, will finally answer this question. Cladribine, because of the known teratogenicity, should not be used in pregnancy, but also with caution in young female of potential child bearing capacity. In addition, as cladribine most likely alters viral immunosurveillance, it should not be used in combination with other immunosupressives such as natalizumab or mitoxantrone, and even pretreatment with these agents could possibly put patients at higher risks. As efficacy data are strong and oral drugs are highly appreciated by most of 
the patients, cladribine could potentially play a role in patients refractory to or patients not tolerating first-line treatment. In any case, individual decisions will be required and based on risk-benefit considerations in dialog with the well-informed patient, supported by high standards of postmarketing safety surveillance programs.

\section{Disclosure}

Drs Kieseier, Wiendl, and Hartung have received honoraria for lecturing, travel expenses for attending meetings, and financial support for research from Bayer Health Care, Biogen Idec, Merck Serono, Novartis, sanofi-aventis, and TEVA. Drs Stüve and Warnke have nothing to disclose.

\section{References}

1. Wiendl H, Toyka KV, Rieckmann P, et al. Basic and escalating immunomodulatory treatments in multiple sclerosis: current therapeutic recommendations. J Neurol. 2008;255(10):1449-1463.

2. The IFNB Multiple Sclerosis Study Group. Interferon beta-1b is effective in relapsing-remitting multiple sclerosis. I. Clinical results of a multicenter, randomized, double-blind, placebo-controlled trial. Neurology. 1993;43(4):655-661.

3. Paty DW, Li DK. Interferon beta-1b is effective in relapsing-remitting multiple sclerosis. II. MRI analysis results of a multicenter, randomized, double-blind, placebo-controlled trial. UBC MS/MRI Study Group and the IFNB Multiple Sclerosis Study Group. Neurology. 1993;43(4): 662-667.

4. PRISMS (Prevention of Relapses and Disability by Interferon beta-1a Subcutaneously in Multiple Sclerosis) Study Group. Randomised double-blind placebo-controlled study of interferon beta-1a in relapsing/ remitting multiple sclerosis. Lancet. 1998;352(9139): 1498-1504.

5. PRISMS Study Group and the University of British Columbia MS/MRI Analysis Group. PRISMS-4: long-term efficacy of interferon-beta-1a in relapsing MS. Neurology. 2001;56(12):1628-1636.

6. Li DK, Paty DW. Magnetic resonance imaging results of the PRISMS trial: a randomized, double-blind, placebo-controlled study of interferonbeta1a in relapsing-remitting multiple sclerosis. Prevention of relapses and disability by Interferon-beta1a subcutaneously in multiple sclerosis. Ann Neurol. 1999;46(2):197-206.

7. Liu C, Blumhardt LD. Randomised, double blind, placebo controlled study of interferon beta-1a in relapsing-remitting multiple sclerosis analysed by area under disability/time curves. J Neurol Neurosurg Psychiatry. 1999;67(4):451-456.

8. Johnson KP, Brooks BR, Cohen JA, et al. Copolymer 1 reduces relapse rate and improves disability in relapsing-remitting multiple sclerosis: results of a phase III multicenter, double-blind placebo-controlled trial. Neurology. 1995;45(7):1268-1276.

9. Comi G, Filipi M, Wolinsky JS; for the European/Canadian Glatiramer Acetate Study Group. European/Canadian multicenter, double-blind, randomized, placebo-controlled study of the effects of glatiramer acetate on magnetic resonance imaging-measured disease activity and burden in patients with relapsing multiple sclerosis. Ann Neurol. 2001; 49:290-297.

10. Jacobs LD, Cookfair DL, Rudick RA, et al. Intramuscular interferon beta-1a for disease progression in relapsing multiple sclerosis. The Multiple Sclerosis Collaborative Research Group (MSCRG). Ann Neurol. 1996;39(3):285-294.

11. Simon JH, Jacobs LD, Campion M, et al. Magnetic resonance studies of intramuscular interferon beta-1a for relapsing multiple sclerosis. The Multiple Sclerosis Collaborative Research Group. Ann Neurol. 1998; 43:79-87.
12. Hartung HP. High-dose, high-frequency recombinant interferon beta-1a in the treatment of multiple sclerosis. Expert Opin Pharmacother. 2009; 10:291-309.

13. Perumal J, Filippi M, Ford C, et al. Glatiramer acetate therapy for multiple sclerosis: a review. Expert Opin Drug Metab Toxicol. 2006; 2:1019-1029.

14. Francis G. Benefit-risk assessment of interferon-beta therapy for relapsing multiple sclerosis. Expert Opin Drug Saf. 2004;3:289-303.

15. Durelli L, Verdun E, Barbero P, et al. Independent Comparison of Interferon (INCOMIN) Trial Study Group. Every-other-day interferon beta- $1 \mathrm{~b}$ versus once-weekly interferon beta- $1 \mathrm{a}$ for multiple sclerosis: results of a 2-year prospective randomised multicentre study (INCOMIN). Lancet. 2002;359:1453-1460.

16. Mikol DD, Barkhof F, Chang P, et al. Comparison of subcutaneous interferon beta-1a with glatiramer acetate in patients with relapsing multiple sclerosis (the REbif vs Glatiramer Acetate in Relapsing MS Disease [REGARD] study): a multicentre, randomised, parallel, openlabel trial. Lancet Neurol. 2008;7(10):903-914.

17. Cadavid D, Wolansky LJ, Skurnick J, et al. Efficacy of treatment of MS with IFNbeta-1b or glatiramer acetate by monthly brain MRI in the BECOME study. Neurology. 2009;72(23):1976-1983.

18. O'Connor P, Filippi M, Arnason B, et al. 250 mug or 500 mug interferon beta- $1 \mathrm{~b}$ versus $20 \mathrm{mg}$ glatiramer acetate in relapsing-remitting multiple sclerosis: a prospective, randomised, multicentre study. Lancet Neurol. 2009;8(10):889-897.

19. Barbero P, Bergui M, Versino E, et al. INCOMIN Trial Study Group. Every-other-day interferon beta-1b versus once-weekly interferon beta-1a for multiple sclerosis (INCOMIN Trial) II: analysis of MRI responses to treatment and correlation with Nab. Mult Scler. 2006;12: 72-76.

20. Schwid SR, Thorpe J, Sharief M, et al. EVIDENCE (Evidence of Interferon Dose-Response: European North American Comparative Efficacy) Study Group; University of British Columbia MS/MRI Research Group. Enhanced benefit of increasing interferon beta-1a dose and frequency in relapsing multiple sclerosis: the EVIDENCE Study. Arch Neurol. 2005;62:785-792.

21. Panitch H, Goodin DS, Francis G, et al. EVIDENCE Study Group. EVidence of Interferon Dose-response: European North American Comparative Efficacy; University of British Columbia MS/MRI Research Group. Randomized, comparative study of interferon beta-1a treatment regimens in MS: The EVIDENCE Trial. Neurology. 2002; 59:1496-1506.

22. Panitch H, Goodin D, Francis G, et al. EVIDENCE (EVidence of Interferon Dose-response: European North American Comparative Efficacy) Study Group and the University of British Columbia MS/ MRI Research Group. Benefits of high-dose, high-frequency interferon beta- $1 \mathrm{a}$ in relapsing-remitting multiple sclerosis are sustained to 16 months: final comparative results of the EVIDENCE trial. J Neurol Sci. 2005;239:67-74.

23. Lublin FD. When marketing and science intersect: do patients with MS benefit? Neurology. 2002;59:1480-1481.

24. Kieburtz K, McDermott M. Needed in MS: Evidence, not EVIDENCE. Neurology. 2002;59:1482-1483.

25. Cohen BA, Rieckmann P. Emerging oral therapies for multiple sclerosis. Int J Clin Pract. 2007;61:1922-1930.

26. Río J, Porcel J, Téllez N, et al. Factors related with treatment adherence to interferon beta and glatiramer acetate therapy in multiple sclerosis. Mult Scler. 2005;11:306-309.

27. Cox D, Stone J. Managing self-injection difficulties in patients with relapsing-remitting multiple sclerosis. J Neurosci Nurs. 2006;38: 167-171.

28. Cohen BA. Adherence to disease-modifying therapy for multiple sclerosis. Int J MS Care. 2006; Suppl:32-37.

29. Cramer JA, Cuffel BJ, Divan V, et al. Patient satisfaction with an injection device for multiple sclerosis treatment. Acta Neurol Scand. 2006; 113:156-162.

30. Tremlett HL, Oger J. Interrupted therapy: stopping and switching of the beta-interferons prescribed for MS. Neurology. 2003;61:551-554. 
31. Ransohoff RM. Natalizumab for multiple sclerosis. NEngl J Med. 2007; 356(25):2622-2629.

32. Rice GPA, Hartung H, Calabresi PA. Anti-alpha4 integrin therapy for multiple sclerosis: mechanisms and rationale. Neurology. 2005;64(8): 1336-1342.

33. Polman CH, O'Connor PW, Havrdova E, et al. A randomized, placebocontrolled trial of natalizumab for relapsing multiple sclerosis. $\mathrm{N} \mathrm{Engl}$ J Med. 2006;354(9):899-910.

34. Rudick RA, Stuart WH, Calabresi PA, et al. Natalizumab plus interferon beta-1a for relapsing multiple sclerosis. $N$ Engl J Med. 2006;354(9): 911-923.

35. Kleinschmidt-DeMasters BK, Tyler KL. Progressive multifocal leukoencephalopathy complicating treatment with natalizumab and interferon beta-1a for multiple sclerosis. $N$ Engl J Med. 2005;353(4): 369-374.

36. Langer-Gould A, Atlas SW, Green AJ, Bollen AW, Pelletier D. Progressive multifocal leukoencephalopathy in a patient treated with natalizumab. $N$ Engl J Med. 2005;353(4):375-381.

37. Van Assche G, Van Ranst M, Sciot R, et al. Progressive multifocal leukoencephalopathy after natalizumab therapy for Crohn's disease. N Engl J Med. 2005;353(4):362-368.

38. Hartung H. New cases of progressive multifocal leukoencephalopathy after treatment with natalizumab. Lancet Neurol. 2009;8(1): 28-31.

39. Lindå H, von Heijne A, Major EO, et al. Progressive multifocal leukoencephalopathy after natalizumab monotherapy. $N$ Engl J Med. 2009;361:1081-1087.

40. Wenning W, Haghikia A, Laubenberger J, et al. Treatment of progressive multifocal leukoencephalopathy associated with natalizumab. $N$ Engl J Med. 2009;361:1075-1080.

41. Molloy ES, Calabrese LH. Therapy: targeted but not trouble-free: efalizumab and PML. Nat Rev Rheumatol. 2009;5(8):418-419.

42. Carson KR, Evens AM, Richey EA, et al. Progressive multifocal leukoencephalopathy after rituximab therapy in HIV-negative patients: a report of 57 cases from the research on adverse drug events and reports project. Blood. 2009;113:4834-4840.

43. Coles AJ, Compston DAS, Selmaj KW, et al. Alemtuzumab vs interferon beta-1a in early multiple sclerosis. $N$ Engl J Med. 2008;359(17): 1786-1801.

44. Kieseier BC, Wiendl H. Oral disease-modifying treatments for multiple sclerosis: the story so far. CNS Drugs. 2007;21(6):483-502.

45. Osterberg L, Blaschke T. Adherence to medication. $N$ Engl J Med. 2005;353(5):487-497.

46. Giovannoni G, Comi G, Cook S, et al. A placebo-controlled trial of oral cladribine for relapsing multiple sclerosis. N Engl J Med. 2010;362(5): 416-426.

47. Kappos L, Radue E, O'Connor P, et al. A placebo-controlled trial of oral fingolimod in relapsing multiple sclerosis. N Engl J Med. 2010; 362(5):387-401

48. Cohen JA, Barkhof F, Comi G, et al. Oral fingolimod or intramuscular interferon for relapsing multiple sclerosis. N Engl J Med. 2010;362(5): 402-415

49. Carroll WM. Oral therapy for multiple sclerosis - sea change or incremental step? N Engl J Med. 2010;362(5):456-458.

50. Carson DA, Wasson DB, Taetle R, Yu A. Specific toxicity of 2 chlorodeoxyadenosine toward resting and proliferating human lymphocytes. Blood. 1983;62:737-743.

51. Carson DA, Kaye J, Seegmiller JE. Lymphospecific toxicity in adenosine deaminase deficiency and purine nucleoside phosphorylase deficiency: possible role of nucleoside kinase(s). Proc Natl Acad Sci US A. 1977;74:5677-5681.

52. Sipe JC. Cladribine tablets: a potential new short-course annual treatment for relapsing multiple sclerosis. Expert Rev Neurother. 2010; 10(3):365-375.

53. Liliemark J. The clinical pharmacokinetics of cladribine. Clin Pharmacokinet. 1997;32:120-131.
54. Kawasaki H, Carrera CJ, Piro LD, Saven A, Kipps TJ, Carson DA. Relationship of deoxycytidine kinase and cytoplasmic 50-nucleotidase to the chemotherapeutic efficacy of 2-chlorodeoxyadenosine. Blood. 1993;81:597-601.

55. Griffig J, Koob R, Blakley RL. Mechanisms of inhibition of DNA synthesis by 2-chlorodeoxyadenosine in human lymphoblastic cells. Cancer Res. 1989;49:6923-6928.

56. Rieckmann P, Comi G, Cook S, et al. Effects of cladribine tablets on peripheral lymphocyte subtypes implicated in multiple sclerosis immunopathogenesis: surface marker analysis for a subset of patients from the 96 week, Phase III, double-blind, placebo-controlled CLARITY study. Meeting Abstract. Annual Congress of European Committee for Treatment and Research in Multiple Sclerosis (ECTRIMS), Duesseldorf, Germany, 2009 Sep 9-12. Mult Scler. 2009;15:S248-S249.

57. Salvat C, Curchod ML, Guedj E, et al. Cellular expression profiling of genes involved in the cladribine metabolic pathway: insights into mechanism of action in multiple sclerosis. Procedings and Abstracts of the Annual Congress of European Committee for Treatment and Research in Multiple Sclerosis (ECTRIMS). Dusseldorf, Germany, 2009 Sep 9-12 (Poster presentation P280).

58. Rice GP, Filippi M, Comi G. Cladribine and progressive MS: clinical and MRI outcomes of a multicenter controlled trial. Cladribine MRI Study Group. Neurology. 2000;54:1145-1155.

59. Hartung H, Aktas O, Kieseier B, Giancarlo Comi GC. Development of oral cladribine for the treatment of multiple sclerosis. J Neurol. 2010; 257(2):163-170

60. Soelberg-Sorensen P, Comi G, Cook S, et al. Effects of cladribine tablets on haematological profiles in patients with relapsing-remitting multiple sclerosis (RRMS) in the 96 week, phase III, double-blind, placebo-controlled CLARITY study. Meeting Abstract. Annual Congress of European Committee for Treatment and Research in Multiple Sclerosis (ECTRIMS), Dusseldorf, Germany, 2009 Sep 9-12. Mult Scler. 2009;15:S137.

61. Kopadze T, Dobert M, Leussink VI, Dehmel T, Kieseier BC. Cladribine impedes in vitro migration of mononuclear cells: a possible implication for treating multiple sclerosis. Eur J Neurol. 2009;16:409-412.

62. Mitosek-Szewczyk K, Stelmasiak Z, Bartosik-Psujek H, Belniak E Impact of cladribine on soluble adhesion molecules in multiple sclerosis. Acta Neurol Scand. 2010. [Epub ahead of print].

63. Janiec K, Wajgt A, Kondera-Anasz Z. Effect of immunosuppressive cladribine treatment on serum leucocytes system in two-year clinical trial in patients with chronic progressive multiple sclerosis. $\mathrm{Med} \mathrm{Sci}$ Monit. 2001;7:93-98.

64. Bartosik-Psujek H, Belniak E, Mitosek-Szewczyk K, Dobosz B, Stelmasiak Z. Interleukin-8 and RANTES levels in patients with relapsing-remitting multiple sclerosis (RR-MS) treated with cladribine. Acta Neurol Scand. 2004;109:390-392.

65. Laugel B, Challier J, Siegfried C, Chvatchko Y, Weissert R, Galibert L. Cladribine exerts a modulatory effect of T cell activation. Mult Scler. 2008;14:S52-S53.

66. Juliusson G, Christiansen I, Hansen MM, et al. Oral cladribine as primary therapy for patients with B-cell chronic lymphocytic leukemia. J Clin Oncol. 1996;14:2160-2166.

67. Ogura M, Morishima Y, Kobayashi Y, et al. Durable response but prolonged cytopenia after cladribine treatment in relapsed patients with indolent non-Hodgkin's lymphomas: results of a Japanese phase II study. Int J Hematol. 2004;80:267-277.

68. Saven A, Piro LD. 2-Chlorodeoxyadenosine: a newer purine analog active in the treatment of indolent lymphoid malignancies. Ann Intern Med. 1994;120:784-791.

69. Schirmer M, Mur E, Pfeiffer KP, Thaler J, Konwalinka G. The safety profile of low-dose cladribine in refractory rheumatoid arthritis. A pilot trial. Scand J Rheumatol. 1997;26:376-379.

70. Davis JC Jr, Austin H III, Boumpas D, et al. A pilot study of 2-chloro-20-deoxyadenosine in the treatment of systemic lupus erythematosus-associated glomerulonephritis. Arthritis Rheum. 1998;41:335-343. 
71. Beutler E, Sipe JC, Romine JS, Koziol JA, McMillan R, Zyroff J. The treatment of chronic progressive multiple sclerosis with cladribine. Proc Natl Acad Sci U S A. 1996;93:1716-1720.

72. Romine JS, Sipe JC, Koziol JA, Zyroff J, Beutler E. A double-blind, placebo-controlled, randomized trial of cladribine in relapsing-remitting multiple sclerosis. Proc Assoc Am Physicians. 1999;111:35-44.

73. Leist TP, Vermersch P. The potential role for cladribine in the treatment of multiple sclerosis: clinical experience and development of an oral tablet formulation. Curr Med Res Opin. 2007;23:2667-2676.

74. McDonald WI, Compston A, Edan G, et al. Recommended diagnostic criteria for multiple sclerosis: guidelines from the International Panel on the diagnosis of multiple sclerosis. Ann Neurol. 2001;50:121-127.

75. Kurtzke JF. Rating neurologic impairment in multiple sclerosis: an Expanded Disability Status Scale (EDSS). Neurology. 1983;33: 1444-1452.

76. Polman CH, Reingold SC, Edan G, et al. Diagnostic criteria for multiple sclerosis: 2005 revisions to the "McDonald Criteria". Ann Neurol. 2005; 58(6):840-846.

77. Cheson BD, Vena DA, Barrett J, Freidlin B. Second malignancies as a consequence of nucleoside analog therapy for chronic lymphoid leukemias. J Clin Oncol. 1999;17:2454-2460.
78. Kurzrock R, Strom SS, Estey E, et al. Second cancer risk in hairy cell leukemia: analysis of 350 patients. J Clin Oncol. 1997;15:1803-1810.

79. Cook S. A combined analysis of data from four randomized, double-blind, placebo-control led trials of parenteral cladribine and one open-label pilot study to assess the safety and tolerability profile of repeated periods of cladribine treatment in patients with progressive or relapsing multiple sclerosis (P02.180). Neurology (American Academy of Neurology Meeting, Chicago 2008).

80. Kappos L, Antel J, Comi G, et al. Oral fingolimod (FTY720) for relapsing multiple sclerosis. N Engl J Med. 2006;355(11):1124-1140.

81. O'Connor PW, Li D, Freedman MS, et al. A phase II study of the safety and efficacy of teriflunomide in multiple sclerosis with relapses. Neurology. 2006;66(6):894-900.

82. Polman C, Barkhof F, Sandberg-Wollheim M, et al. Treatment with laquinimod reduces development of active MRI lesions in relapsing MS. Neurology. 2005;64(6):987-991.

83. Kappos L, Gold R, Miller DH, et al. Efficacy and safety of oral fumarate in patients with relapsing-remitting multiple sclerosis: a multicentre, randomised, double-blind, placebo-controlled phase IIb study. Lancet. 2008;372(9648):1463-1472.
Drug Design, Development and Therapy

\section{Publish your work in this journal}

Drug Design, Development and Therapy is an international, peerreviewed open-access journal that spans the spectrum of drug design and development through to clinical applications. Clinical outcomes, patient safety, and programs for the development and effective, safe, and sustained use of medicines are a feature of the journal, which

\section{Dovepress}

has also been accepted for indexing on PubMed Central. The manuscript management system is completely online and includes a very quick and fair peer-review system, which is all easy to use. Visit http://www.dovepress.com/testimonials.php to read real quotes from published authors.

Submit your manuscript here: http://www.dovepress.com/drug-design-development-and-therapy-journal 